\title{
Differential Expression of Distinct Members of Rho Family GTP- Binding Proteins during Neuronal Development: Identification of Rac1B, a New Neural-Specific Member of the Family
}

\author{
Maria Luisa Malosio, Daniela Gilardelli, Simona Paris, Chiara Albertinazzi, and Ivan de Curtis \\ Cell Adhesion Unit, Department of Biological and Technological Research (DIBIT), San Raffaele Scientific Institute, 20132 \\ Milano, Italy
}

\begin{abstract}
Previous studies on small GTP-binding proteins of the Rho family have revealed their involvement in the organization of cell actin cytoskeleton. The function of these GTPases during vertebrate development is not known. With the aim of understanding the possible role of these proteins during neuronal development, we have cloned and sequenced five members expressed in developing chick neural retinal cells. We have identified four chicken genes, cRhoA, cRhoB, cRhoC, and cRac1A, homologous to known human genes, and a novel Rac gene, $c$ Rac1B. Analysis of the distribution of four of the identified transcripts in chicken embryos shows for the first time high levels of expression of Rho family genes in the vertebrate developing nervous system, with distinct patterns of distribution for the different transcripts. In particular, $c R h o A$ and cRac1A gene expression appeared ubiquitous in the whole
\end{abstract}

embryo, and the $c R h o B$ transcript was more prominent in populations of neurons actively extending neurites, whereas the newly identified $C R a c 1 B$ gene was homogeneously expressed only in the developing nervous system. Temporal analysis of the expression of the five genes suggests a correlation with the morphogenetic events occurring within the developing retina and the retinotectal pathway. Expression of an epitope-tagged cRac1B in retinal neurons showed a diffuse distribution of the protein in the cell body and along neurites.

Taken as a whole, our results suggest important roles for ubiquitous and neural-specific members of the Rho family in the acquisition of the mature neuronal phenotype.

Key words: Rho GTPases; neuronal development; chick embryo; neural retinal cells; retinotectal pathway; dorsal root ganglia
The actin cytoskeleton plays a fundamental role in several aspects of cell life, including adhesion, migration, and cytokinesis. Several actin binding proteins take part in the organization of the actin cytoskeleton and contribute to its dynamic properties. Recent studies have shown that components of the Rho family, which belong to the Ras superfamily of small GTPases, are involved in the reorganization of the actin cytoskeleton and of the associated sites of cell adhesion to the extracellular matrix (Hall, 1994). In particular, microinjection experiments have demonstrated that RhoA is essential for the assembly of focal adhesions and the associated actin stress fibers (Ridley and Hall, 1992) and that Rac1 is required for growth factor-induced membrane ruffling (Ridley et al., 1992), whereas Cdc42 triggers the formation of filopodia (Nobes and Hall, 1995). Neurite outgrowth can be considered as a particular form of cell motility in which actin dynamics during growth cone navigation evolves into stabiliza-

\footnotetext{
Received Jan. 19, 1997; revised June 6, 1997; accepted June 11, 1997.

This work was supported by Telethon-Italy (Grant No. 791). M.L.M. was supported by a postdoctoral fellowship from the University of Milano. We are grateful to Dr. Elena Rugarli (TIGEM, Milano, Italy) and Dr. Elena Zanaria (University of Pavia) for providing chick embryo sections for in situ hybridization; Dr. C. Nottenburg (Fred Hutchinson Cancer Research Center, Seattle, WA) for the E10 chick cDNA library; Dr. B. Ranscht (La Jolla Cancer Research Foundation, La Jolla, CA) for the E13 chick brain cDNA library; and Dr. M. A. Impagnatiello for the pcDNA-I-Amp-HA plasmid. We also thank Dr. R. M. Alvarado-Mallart and Dr. E. Gallego (Institut National de la Santé et de la Recherche Médicale U-106, Paris, France) for their help in the interpretation of the results from the in situ hybridization studies, and Dr. Edoardo Boncinelli and Dr. Jacopo Meldolesi for critical reading of this manuscript.

Correspondence should be addressed to Ivan de Curtis, Cell Adhesion Unit, Department of Biological and Technological Research (DIBIT), San Raffaele Scientific Institute, via Olgettina 58, 20132 Milano, Italy.

Copyright (C) 1997 Society for Neuroscience $0270-6474 / 97 / 176717-12 \$ 05.00 / 0$
}

tion of the cytoskeleton and neurite elongation (Tanaka and Sabry, 1995). The behavior of growth cones can therefore be compared with that of the leading edge of spreading or migrating fibroblasts, in which the dynamic adhesive interactions with the substrate are accompanied by a continuous reorganization of the actin cytoskeleton.

In line with this interpretation, recent evidence has accumulated that suggests a role for the Rho family GTPases in neuritogenesis (Mackay et al., 1995; Luo et al., 1996). In fact, activation of Rho proteins by lysophosphatidic acid, thrombin, or sphingosine-1-phosphate leads to growth cone collapse and retraction of neurites in N1E-115 neuroblastoma cells (Jalink et al., 1994; Postma et al., 1996), and these effects can be prevented by pretreatment of the cells with the Clostridium botulinum C3 exoenzyme, which specifically ADP-ribosylates Rho proteins. Furthermore, two Drosophila homologs of the Rho family GTPases, Drac1 and Dcdc42, are highly expressed in the Drosophila developing nervous system, and mutants of these proteins cause distinct defects in neuronal development (Luo et al., 1994). These data raise the possibility that components of the Rho family of small GTPases may play a role in neuronal development in vertebrates as well. So far, however, the nature and distribution of the different GTPases of the Rho family expressed during vertebrate development remain undefined. With the aim of studying the role of Rho GTPases in the development of the neuronal phenotype, we have now identified by molecular cloning various components expressed in chicken developing neurons. The identified cDNAs have been used for in situ hybridization analysis to look at the expression of the corresponding transcripts in the entire chicken embryo. 


\section{CRac1A}

cet cgc tco gca gce acg ATG CAG GCC ATC AAG TG GG GTG GG GGC GAC GGT GCT GTA
met gin ala ile lys Gs val val vol gly asp gly ala val GGT AM ACA TGC CTA CTC ATC AGT TAC ACA ACC AAT GCG TIT CCT GGG GA TAC ATA CCC 120
gly lys thr Cys leu leu ile ser tyr thr thr asn alo phe pro gly glu tyr ile pro 34 ACA GTC TT GAC AAC TAC TCT GCT AAT GA ATG GTI GAT GGC AAA CCA GTC MAT CTC GGC IBO
thr val phe aSp asn tyr ser ala ass val met val asp gly lys pro val asn leu gly CTG TGG GAT ACA GCT GG CAA GAG GAC TAT GAC ACA CTA CGC CCA CTC TCC TAC CCC CAA 240 leu trp asp thr ala gly gin glu asp tyr asp arg leu arg pro leu ser tyr pro gin 74 ACA GAT GTC TC TA ATC TGC TIT TCC CTT GTG AGT CCT GCT TCC TIT GAA MAT GTC CGT 300
thr asp val phe leu ile Cys phe ser leu vai ser pro ala ser phe glu asn val arg GCT AAG TGG TAT CCT GAG GTG CGG CAC CAT TGC CCC AAC ACT CCC ATC ATT TAA GGG GGT 360 ala lys trp tyr pro glu val arg his his Cys pro osn thr pro ile ile leu val gly 114 ACC AAA CTT GAT CTC AGA GAT GAT AAA GAC ACT ATT GAA AAA CTG AAG GAG AAG MAG CTG 420
thr lys leu asp leu arg asp asp lys osp thr ile glu lys leu lys glu lys lys leu 134 ACT CCT ATC ACC TAC CCA CAG GEC CTT GCC ATG GCA AMA GAG ATA GGT GCA GTG MM TAC 480 thr pro ile thr tyr pro gln giy leu ala met ala lys glu ile gly ala val lys tyr 154 CTA GAA TCC TCA GCA CTT ACA CAG CGA GGC CTC MAG ACA GTG TTT CAC CAA GCT ATC CGA 540
leu glu CYs ser ala leu thr gin arg gly leu lys thr vol phe asp giu ala ile arg 174 GCA GTT CTG TGC CCC CCG CCT GA AAG AAG AGG AAG AGA AMA TGT CTG CTG CTG TAA agt 600
ola val leu cys pro pro pro val lys lys arg lys arg lys Cys leu leu leu OCH
192

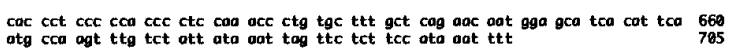

\section{CRhoA}

ATG GCA GCC ATT CGA AMA NAG TTG GTC ATA GTG GGC GAC GGT GCC TGC GGG MAG ACC TGT Wet ala ala ile arg lys lys leu val ile val gly asp gly al a cys gly lys thr cys 2

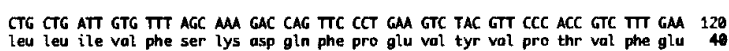
MAT TAT GTA GCA GAT ATT GAA GTG GAT GGA MAG CAG GGG GAG TTG GCT TTG TGG GAT ACA 180 GCA GGA CAG GAA GAC TAC GAT CGA CTT AGA CCG CTT TCT TAT CCA GAT ACT GAT GT ATA 240
ola gly gln glu asp tyr asp arg leu arg pro leu ser tyr pro osp thr OSp val ile CTT ATG TGT TIT TCA ATC GAT AGT CCT GAT AGT TTA GAA AAC ATC CCG GAG AGG TGG ACC 300 CCG GAA GTG AAG CAT TTC TGT CCC AAC GGG CCT ATC ATC TTG GTA GGA AAC AAG AAG GAC 360 CCG GAA GTG AAG CAT TTC TGT CCC AAC GTG CCT ATC ATC TTG GTA GGA AAC AAG AAG GAC 360
pro glu val lys his phe cys pro asn val pro ile ile leu vol gly asn lys lys asp 120 CTG AGG AAT GAC GAG CAC ACA AGA CGA GAG CTG GCC AAA ATG AAG CAG CAG CCT GTC AMA 420 CCT GAG GM GGA AGA GAT ATG GCA AAC CGC ATC GGT GCA TIT GGA TAT ATG GaG TGT TCG 480 CCT GAG GA GGA AGA GAT ATG GCA AAC CGC ATC GGT GCA TTT GGA TAT ATG GAG TCT TCG 480
pro glu glu gly arg asp met ala asn arg ile giy ala phe gly tyr met glu cys ser 168 GCA AMG ACC AAA GAC GGT GTC AGG GAG GTT TT GAA ATC GCC ACT AGA GCT GCT TTC CMA 540
ala lys thr lys asp gly val arg glu val phe glu met ala thr arg ala ala leu gin 180 GCC CGG CGT GGC AAG AMA MAG TCC GGG TGC CTT CTC TTA TAA agr gtg grc aga gga aga 600
ala arg arg gly lys lys lys ser gly Cys lew leu leu OCH

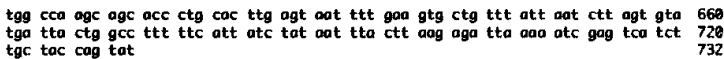

\section{CRhoC}

\section{CRac1B}

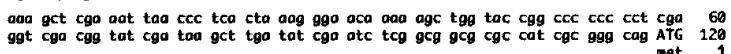

CAG GCG ATC AAG TGT GTG GTG GTG GGC GAC GGA GCT GTA GGG AAG ACC TGC TTG CTG ATC 180 gin alo ile lys cys val val val gly asp gly alo val gly lys thr cys leu leu ile 21 AGT TAC ACC ACG MT GCC TT CCT GGA GAG TAC ATC CCC ACT GTA TTT GAT AAC TAT TCT 240
ser tyr thr thr osn ala phe pro gly glu tyr ile pro thr vol phe osp asn tyr ser 41 GCC Aat GT ATG GTA GaT GGg AaG CCA GTG AAT CTA GGC CTC TGG GAT ACA GCA GGA CAa 360 ala asn val met val asp gly lys pro val asn leu gly leu trp asp thr ala gly gln 61 \begin{tabular}{l} 
GAG GAT TAT GAC CGA CTG CGG CCT CTT TCC TAC CCA CAG ACA GAT GTT TTC TG ATT TGC 360 \\
glu asp tyr asp arg leu arg pro leu ser tyr pro gln thr asp val phe leu ile cys \\
\hline
\end{tabular} TTC TCC CTC GTG AGT CCA GCC TCC TIT GAG Aat GTC AGA GCC MAG TGG TAC CCT GAG GTC 420 phe ser leu val ser pro ala ser phe glu ast val arg ala hys trp tyr pro glu vol 10 CGA CAC CAC TGC CCA AAT ACA CCT ATC ATC TTG GG GGC ACC AAG CTG GAC TTA AGG GAT 480
arg his his cys pro asn thr pro i le ile leu val gly thr lys leu asp leu arg asp 121 gat aag gac acc ott gaa agg tta cgt gat AAG AAA CTG GCT CCC ATC ACC TAC CCC CAA 540
asp lys asp thr ile glu arg leu arg asp lys lys leu ala pro ile thr tyr pro gln 141 GGT TTG GCC ATG GCT CGG GAG ATT GGC TCG GTA MG TAC CTT GAG TGC TCT GCC CTG ACA 600 GGT TTG GCC ATG GCT CGG GAG ATT GGC TCG GTA AMG TAC CTT GAG TGC TCT GCC CTG ACA 620
gly leu ala met ala arg glu ile gly ser val lys tyr leu glu cys ser ala leu thr 161 CAG CGG GGC TTG AAG ACG GTG TIT GAT GAA GCC ATC CGG GCT GTG CTC TGC CCA CCG CCC 666 $\begin{array}{lll}\text { GG AAG AAG CCT GGC MA AGG TGC ACC GG TTC TGA ggg etg tgg cet ogg tgc tgg } & 717 \\ \text { val lys lys pro gly lys lys cys thr val phe OPA } & 193\end{array}$

\section{CRhoB}

goc tca cto tag gcg out tgg agc tcc acg cgg tgg cgg ccg ctc tag aac tag tgg atc. 60
cce cgg gct gca gga att ccg gce atc gtc ctg ctg cac ggc aag gcc agc ttg gcg agc 120 ctg gac ATG GCC GCC ATC CGC AAG AAG CTG GTG GG GG GGA GAC GGC GCC TGT GGC AAG
met ala ola ile arg lys lys leu val val val gly asp gly ala cys gly lys
18 ACC TCC CTC CTC ATC GTC TC ACC AAG GAC GAG TIC CCC GAG GTT TAC GTG CCC ACC GTC 240
thr Cys leu leu ile val phe ser lys asp glu phe pro glu val tyr val pro thr val 38

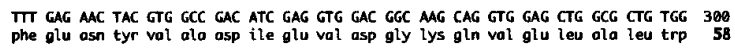
GAC ACG GCC GGC CAG GAC GAC TAC GAC CGC CTG CGC CCT CTC TCC TAC CCA GAC ACG GAC 360
asp thr ola gly gin glu aSp tyr asp arg leu arg pro leu ser tyr pro asp thr asp 78 GTG ATC CTC ATG TGC TIC TCA GTG GAC AGC CCG GAC TCG CTG GAG AAC ATC CCG GAG AAG 420 GTG ATC CTC ATG TGC TC TCA GTG GAC AGC CCG GAC TCG CTG GAC AAC ATC CCG GAG AAG 420
val ile leu met cys phe ser vol asp ser pro asp ser leu glu asn ile pro glu lys 98 TGG GTG CCC GAA TTC AAG CAC TTC TGC CCC AAC GTC CCC ATC ATC CTC GTG GCC AAC AAG 480 trp val pro glu val lys his phe cys pro asn val pro ile ile leu val ala asn lys 118 and CAC CTG COC AAC GAC GAC CAC GTC CGT AAC GAC CTC CCC CCC ATC AAC CAG CAG CCG 540
lys asp leu arg asn aSp glu his val arg asn glu leu ala arg met lys gln glu pro 138 GTC CGC ACT GAG GAT GCC CGC GCC ATC OCC ATC COC ATC CAG GCC TAC GAC TAC CTS GAC val arg thr glu osp gly arg ala met ala ile arg ite gln alo tyr asp tyr leu glu 158 TEC TCG GCC AAG ACC AAG GAG GGT GTG CGG GAG GTC ITT GAG ACG GCC ACC CGG GCG GCC 66 . cys ser ala lys thr lys glu gly val arg glu val phe glu thr ato thr arg ala ala 17 TIG CAG AAG CGC TAC GGC ACT CAG AAC GGC TGC ATC MAT TGC TGC AAG GTC CTA TAG 996720
leu gin lys arg tyr gly thr gin asn gly Cys ile asn Cys Cys lys val leu AMG ccg gct gga gcc ggc gct $9 g 9$ coc ggc tct ggg tca cct gtt ggc agg cgg aga gga gct 780 g9g gca cge otg cac aca gca tct gce tgt

\footnotetext{
$\begin{array}{ll}\text { TGC } & 3 \\ \text { cys } & 20\end{array}$

CTG CTG ATC GTC TTC AGC AAG GAC CAG TTC CCT GAG GTC TAC GTG CCA ACT GTG TIT GAG 63

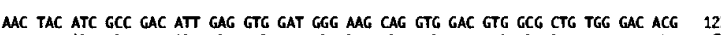
AAC TAC ATC GCC GAC ATT GAC GTC GAT GGG AAG CAG GTG GAC GTG GCG CTC TGG GAC ACG
asn tyr ile ala asp ile glu val asp gly lys gln val asp val alo leu trp asp thr GCT GCG CAA GAG GAC TAC GAC CGG CTG CGG CCC CTC TCA TAC CCA GAC ACC GAT GTC ATC 183 CTC ATG TGC TIT TCT ATI GAC AGC CCA GAC AGC CTC GAG AAC ATC CCT GAG MAG TGC ACC 243 leu met cys phe ser ile asp ser pro asp ser leu glu osn ile pro glu lys trp thr 10 CCG GAG GTC AAG CAC TTC TCC CCC AAC GTG CCC ATC ATC CTG GTG GGG AAC ACG AAC GAC 393 CTG CGC AaC GAT GAG CAC ACA CGG CGG GAA CTG GCA AaG ATG AaG Cag GAG CCT GTG AAG 363 CTG CGC AAC GAT GAG CAC ACA CGG CGG GAA CTG GCA AAG ATG MAG CAG GAG CCT GTC AAG 363
leu arg asn asp glu his thr arg arg glu leu ala lys met lys gln glu pro val lys 140 CCA GA GAG GGG AGA GAC ATG GCC AAC AGG ATC MT GCC TTC GGC TAC CTC GAG TGC TCG 423
pro glu glu gly arg aSp met ala oSn arg ile asn ala phe gly tyr leu giu cys ser 160 GCC AMG ACC AAG GAG GGC GTG CGG GAG GTC TIT GAG ATG GCC ACA CGT GCG GGC CTG CAG 483 ala lys thr lys glu gly vol arg glu val phe glu met ala thr arg ala gly leu gln 18 GTC CGC MG AAC AAG MAG CGC CGG GGC TGC CCG CTG CTG TGA gca ggg agg gct ccg tge 543
val arg lys asn lys lys arg org gly cys pro lew leu OPA

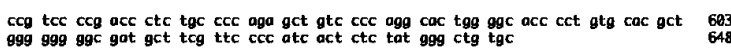

Figure 1. Nucleotide sequences of the chick Rho family GTPases cDNAs expressed in embryonic neural retina, and deduced primary sequences of the encoded polypeptides. The sequence data are available from GenBank under accession numbers U79757 (cRhoA), U79758 (cRhoB), U79759 ( $c R h o C)$, $\mathrm{U} 79755$ (cRac1A), and U79756 (cRac1B).

The data presented in this paper show that developing retinal neurons express the mRNAs of at least five different components of the Rho family of GTPases, including a new Rac protein, which are differentially expressed during the development of the neural retina. Furthermore, the analysis of the distribution of four of the identified transcripts shows that they are strongly and specifically expressed in various areas of the developing CNS and peripheral nervous system.

\section{MATERIALS AND METHODS}

Reagents. Fertilized chicken eggs were purchased from Allevamento Giovenzano (Vellezzo Bellini, Italy). Taq polymerase was from Promega 
A

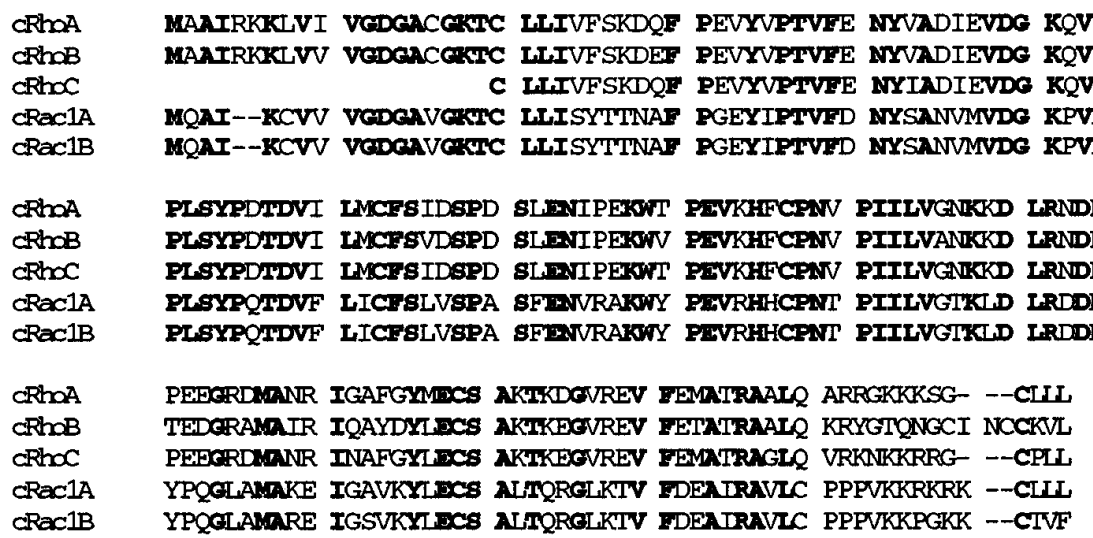

B

\begin{tabular}{|c|c|c|c|c|c|c|c|c|c|c|}
\hline & cRhoA & cRhoB & & & & & & & & \\
\hline $\begin{array}{l}\text { cRhoA } \\
\text { cRhoB }\end{array}$ & $\begin{array}{l}100 \\
72.1\end{array}$ & 100 & cRhoC & cRaclA & & & & & & \\
\hline cRhoC & 76.2 & 77.8 & 100 & & cRac1B & & & & & \\
\hline $\begin{array}{l}\text { cRacliA } \\
\text { cRac1B }\end{array}$ & 56.6 & 56.8 & $\begin{array}{l}59.2 \\
58.9\end{array}$ & 100 & & hRhoA & bPhol & & & \\
\hline $\begin{array}{l}\text { CRaclB } \\
\text { hRhoA }\end{array}$ & 83.5 & 75.7 & $\begin{array}{l}38.9 \\
77.8\end{array}$ & $\begin{array}{l}78.5 \\
56.6\end{array}$ & 56.6 & 100 & ПR ПIOB & hRhoC & & \\
\hline hRhoB & 72.9 & 90.3 & 78.5 & 56.6 & 56.5 & 69.9 & 100 & & hRacl & \\
\hline hRhoC & 79 & 79.9 & 85.3 & 62 & 62.7 & 78.4 & 79.6 & 100 & & hRac2 \\
\hline hRacl & 63 & 57 & 58.3 & 88.5 & 80.7 & 62.2 & 64.3 & 62 & 100 & \\
\hline hRac2 & 62.9 & 67 & 63.7 & 77.4 & 78.5 & 58.9 & 67 & 66.2 & 78.2 & 100 \\
\hline
\end{tabular}

c

$\begin{array}{lcccccccccc} & \text { cRhoA } & \text { cRhoB } & & & & & & & \\ \text { cRhoA } & 100 & & \text { cRhoC } & & & & & & \\ \text { cRhoB } & 85.5 & 100 & & \text { cRac1A } & & & & & \\ \text { cRhoC } & 92.5 & 83.3 & 100 & & \text { cRac1B } & & & \\ \text { cRac1A } & 59.2 & 56.7 & 56.3 & 100 & & \text { hRhoA } & & & \\ \text { cRac1B } & 57 & 56.7 & 54.6 & 93.8 & 100 & & \text { hRhoB } & & \\ \text { hRhoA } & 100 & 86 & 92 & 59.2 & 57.6 & 100 & & \text { hRhoC } & & \\ \text { hRhoB } & 84.5 & 97.5 & 82.2 & 56.7 & 56.7 & 85 & 100 & & \text { hRac1 } & \\ \text { hRhoC } & 91.7 & 85.5 & 95.4 & 58.6 & 56.6 & 91.7 & 85 & 100 & \text { hRac2 } \\ \text { hRac1 } & 59.7 & 56.7 & 56.3 & 100 & 93.7 & 59.2 & 56.7 & 58.7 & 100 & \\ \text { hRac2 } & 56.3 & 55.2 & 53.5 & 92.2 & 89 & 55.8 & 55.2 & 55.5 & 92.2 & 100\end{array}$

Figure 2. Amino acid and nucleotide sequence comparisons. $A$, Amino acid sequence alignment of $\mathrm{cRhoA}, \mathrm{cRhoB}, \mathrm{cRhoC}$, cRac1A, and cRac1B deduced polypeptides. Identical amino acids are shown in bold type. $B$, Percentages of identity between the coding regions of chick cDNAs $c R h o A$, $c R h o B, c R h o C, c R a c 1 A$, and $c R a c 1 B$ and those of human cDNAs RhoA, RhoB, RhoC, Rac1, and Rac2. C, Percentages of amino acid identities between chick proteins cRhoA, cRhoB, cRhoC, cRac1A, and cRac1B and human proteins RhoA, RhoB, RhoC, Rac1, and Rac2.

(Madison, WI), Klenow fragment of DNA polymerase was from Pharmacia (Uppsala, Sweden), and restriction enzymes were from Boehringer Mannheim (Mannheim, Germany). $\left[\alpha-{ }^{35} \mathrm{~S}\right] \mathrm{dATP}$ and $\left[\alpha^{-}{ }^{32} \mathrm{P}\right] \mathrm{dCTP}$ were from Amersham (Buckinghamshire, UK). Other chemicals were purchased from Sigma-Aldrich (Milan, Italy). Laminin was purified from Engelbreth-Holm Swarm sarcoma as published (Timpl et al., 1979).

Isolation of PCR clones. Total RNA was extracted from E6 retinas by the RNAzolB method (Chomczynski and Sacchi, 1987). Five micrograms of total RNA were converted into complementary DNAs by oligo-dTpriming [oligo-d $\mathrm{T}_{12-18}$; Life Technologies-BRL, Milano, Italy] in the presence of Moloney murine leukemia virus reverse transcriptase (Life Technologies-BRL). Aliquots of the resulting single-stranded cDNA (7.5 ng) were mixed with pairs of degenerate synthetic oligonucleotides and subjected to thermal cycling. Two different sets of degenerate oligonucleotides were used for the amplifications: a set containing the sequences 5'-TTYWSMAARGAYCAGTTCCC (RhoA-1) and 5'-TCACBGGY TCCTGYTTCAT (RhoA-2) coding for amino acid positions 25-31 and $134-140$, respectively, of the human RhoA protein, and a more degenerate set of oligonucleotides containing the sequences $5^{\prime}$-AAR ACNTGYYTNCTSAT (RhoF-1) and 5'-GCHGARCAYTCVADRTA (RhoF-2) coding for amino acid positions 18-23 and 156-161, respectively, of different Rho proteins. PCRs contained $50 \mu \mathrm{l}$ of $50 \mathrm{~mm} \mathrm{KCl}, 10$ $\mathrm{mm}$ Tris- $\mathrm{HCl}, \mathrm{pH} 9.0,1.5 \mathrm{~mm} \mathrm{MgCl}_{2}, 0.1 \%$ Triton X-100, $200 \mu \mathrm{M}$ desoxyribonucleotide triphosphate (dNTP), 100 pmol of each oligonucleotide, $2.5 \mathrm{U}$ of Taq polymerase (Promega), and $1.5 \mu \mathrm{l}$ of cDNA. The first five cycles were performed under low stringency annealing conditions $\left(94^{\circ} \mathrm{C}, 1 \mathrm{~min} ; 43^{\circ} \mathrm{C}, 1 \mathrm{~min} ; 72^{\circ} \mathrm{C}, 1 \mathrm{~min}\right)$; the following 40 cycles were performed at higher stringency $\left(94^{\circ} \mathrm{C}, 1 \mathrm{~min} ; 50^{\circ} \mathrm{C}, 1 \mathrm{~min} ; 72^{\circ} \mathrm{C}, 1.5 \mathrm{~min}\right)$. The $\mathrm{cRhoC}$ clone was isolated by using the "touchdown" PCR technique with RhoF1 and RhoF2 primers (Don et al., 1991). Amplified DNA fragments were subcloned into a pBluescript $\mathrm{KS}^{-} \mathrm{T}$-vector (Marchuk et al., 1991). Plasmid clones containing inserts of appropriate size were subjected to direct sequencing by the dideoxy method (Sanger et al., 1977) and analyzed by the GCG Wisconsin Sequence Analysis Package.

Isolation of cDNA clones from $\lambda$ gt10 libraries. Four full-length clones and a partial clone coding for the different chicken Rho and Rac proteins were isolated either from an embryonic day (E) 10 chicken or an E13 chicken brain cDNA library in $\lambda \mathrm{gt} 10$ [obtained from Dr. C. Nottenburg (Fred Hutchinson Cancer Research Center, Seattle, WA) and Dr. B. Ranscht (Cancer Research Institute, La Jolla, CA), respectively]. The libraries were plated on Escherichia coli strain LE392, and replica filters were screened in duplicate at high stringency according to a modified procedure of Church and Gilbert (1984). Prehybridization was performed for $3 \mathrm{hr}$ at $65^{\circ} \mathrm{C}$ in hybridization buffer $\left(125 \mathrm{mM} \mathrm{Na}_{2} \mathrm{HPO}_{4}, 1 \mathrm{~mm}\right.$ EDTA, $250 \mathrm{~mm} \mathrm{NaCl}$, 7\% SDS, 10\% PEG-8000, 1\% BSA, $100 \mu \mathrm{g} / \mathrm{ml}$ denatured salmon sperm DNA). Hybridizations were performed at $65^{\circ} \mathrm{C}$ 

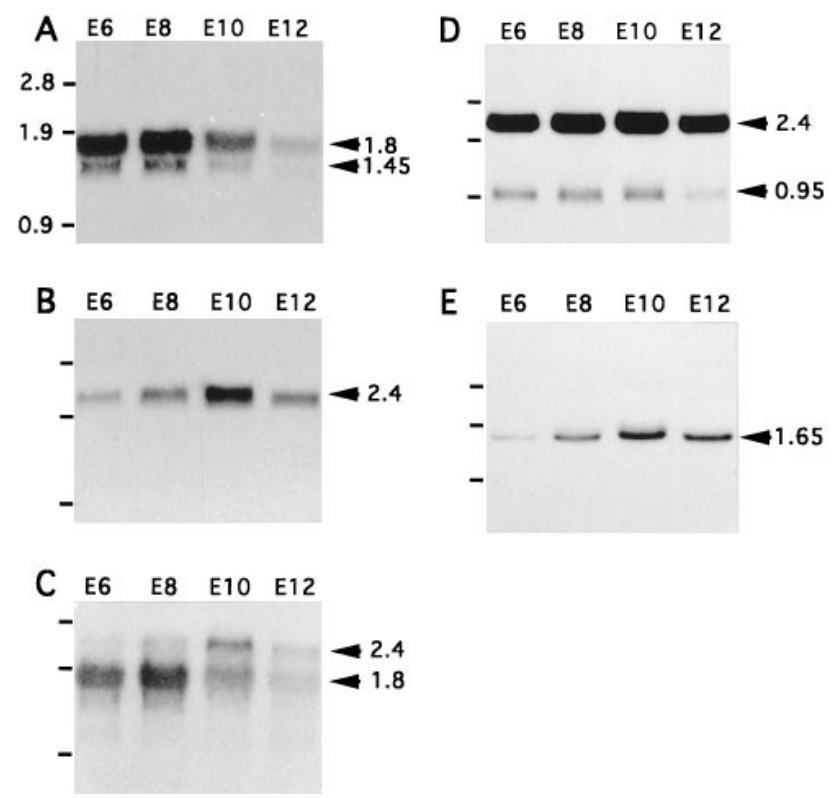

Figure 3. Northern blot analysis of GTPase mRNA levels during neural retina development. Total RNA extracted from E6, E8, E10, and E12 neural retinas was electrophoresed on a $1 \%$ agarose gel and transferred to filters, as described in Materials and Methods. Filters were incubated with ${ }^{32} \mathrm{P}$-labeled probes specific for $c R h o A(A), c R h o B(B), c R h o C(C)$, $c \operatorname{Rac1A}(D)$, or $c \operatorname{Rac1B}(E)$. RNA markers (in kilobases) are indicated to the left of each blot; the size of the transcripts (in kilobases) is indicated to the right.

in the same buffer in the presence of $0.5-1 \times 10^{6} \mathrm{cpm} / \mathrm{ml}$ of ${ }^{32} \mathrm{P}$-labeled probe. Washings were in $0.2 \times \mathrm{SSC}$ at $65^{\circ} \mathrm{C}$. The cDNAs corresponding to the different chicken PCR products were labeled by random priming (Feinberg and Vogelstein, 1983) at a specific activity between $7 \times 10^{8}$ and $1.2 \times 10^{9} \mathrm{cpm} / \mu \mathrm{g}$. cDNAs inserts from positive purified phages were extracted by EcoRI digestion and subcloned into pBluescript $\mathrm{KS}^{-}$. Both strands were sequenced with the T7 sequencing kit (Pharmacia, Uppsala, Sweden) using different specific oligonucleotide primers.

Northern blot analysis. Total RNA was prepared from E6, E8, E10, and E12 chick neural retinas by the RNAzolB method (Chomczynski and Sacchi, 1987). Northern blot analysis of total RNA (20 $\mu \mathrm{g} /$ lane) was performed as described previously (Lehrach et al., 1977; Malosio et al., 1991). Hybridizations and washes were performed under the same high stringency conditions used for the screening of the libraries. Hybridizations took place in hybridization buffer supplemented with ${ }^{32} \mathrm{P}$-labeled probes $\left(0.5-1.0 \times 10^{6} \mathrm{cpm} / \mathrm{ml}\right)$ for $12-16 \mathrm{hr}$ at $65^{\circ} \mathrm{C}$. After high stringency washes $\left(0.2 \times \mathrm{SSC}\right.$ at $\left.65^{\circ} \mathrm{C}\right)$, x-ray films were exposed for 3-7 d to the hybridized filters. RNA blots were reprobed with an $18 \mathrm{~S}$ ribosomal RNA probe. Quantitations of hybridized bands were performed by computer densitometry (Molecular Dynamics, Sunnyvale, CA). The values for the different GTPase transcripts were normalized to the corresponding values obtained for the $18 \mathrm{~S}$ ribosomal RNA.

In situ hybridization. The 370- to 400-bp-long cDNAs obtained by PCR, coding for the different Rho proteins, were used for the preparation of sense and antisense RNA probes to be used for in situ hybridizations. The specificity of hybridization of these probes had been assessed previously by Northern blotting. After linearization of the pBluescript plasmids with the appropriate restriction enzyme, T3 and T7 polymerases were used to generate high specificity ${ }^{35} \mathrm{~S}$-labeled riboprobes by incorporation of $\left[\alpha^{35}\right.$ S $]$ rUTP (Amersham, Arlington Heights, IL) into the transcribed RNA (RNA transcription kit, Stratagene, La Jolla, CA). The DNA template was removed by digestion with DNase I and the labeled RNA probe was purified through a Bio-spin column (Boehringer Mannheim). The purified probe was supplemented with $20 \mathrm{~mm}$ DTT, and an aliquot was counted in scintillation fluid.

For in situ hybridization, paraffin sections of chick embryos were dewaxed, deproteinated, and post-fixed in $4 \%$ paraformaldehyde (Rugarli et al., 1993). The ${ }^{35} \mathrm{~S}$-labeled riboprobes were diluted at $4.2-6.3 \times$ $10^{7} \mathrm{cpm} / \mathrm{ml}(\sim 60 \mathrm{ng} / \mathrm{ml})$ in hybridization buffer containing $50 \%(\mathrm{v} / \mathrm{v})$ formamide, $0.3 \mathrm{M} \mathrm{NaCl}, 10 \mathrm{~mm}$ Tris- $\mathrm{HCl}, \mathrm{pH} 7.6,10 \mathrm{~mm} \mathrm{NaH}_{2} \mathrm{PO}_{4}, \mathrm{pH}$ 6.8, 5 mM EDTA, pH 8.0, 0.2\% (w/v) Ficoll 400, 0.2\% (w/v) polyvinylpyrrolidone, $10 \%(\mathrm{w} / \mathrm{v})$ dextran sulfate, $50 \mathrm{~mm}$ DTT, $0.5 \mathrm{mg} / \mathrm{ml}$ poly ribo A, and $50 \mu \mathrm{g} / \mathrm{ml}$ yeast tRNA, and added to the sections. Sections were incubated overnight at $55^{\circ} \mathrm{C}$ in a humidified chamber. Stringency washes at $64^{\circ} \mathrm{C}$ included several washes in $2 \times \mathrm{SSC}, 50 \%$ formamide, $20 \mathrm{~mm}$ $\beta$-mercaptoethanol, in $4 \times \mathrm{SSC}, 20 \mathrm{~mm}$ Tris- $\mathrm{HCl}, \mathrm{pH} 7.6,1 \mathrm{~mm}$ EDTA, and $30 \mathrm{~min}$ incubation with RNase A $(10 \mu \mathrm{g} / \mathrm{ml})$. Slides were air-dried and exposed to x-ray films for 3-6 d. Subsequently, slides were dipped
Figure 4. Quantitation of the levels of expression of the $c R h o A, c R h o B, c R h o C, c R a c 1 A$, and $c R a c 1 B$ transcripts during retina development. Quantitation was obtained by densitometry on autoradiograms from two experiments such as those shown in Figure 3. For $c R h o A, c R h o C$, and cRac1A transcripts, the values for both hybridizing bands were added (Fig. 3, $A, C$, and $D$, respectively). The values for the different GTPase transcripts were normalized to the values obtained from the corresponding $18 \mathrm{~S}$ ribosomal RNA hybridizations and plotted on a semilogarithmic scale. The E6 expression levels of the different transcripts were considered as $100 \%$. Each value represents the mean obtained from two blots. Quantitation indicated that changes during neural retina development of the individual transcripts for $c R h o A$ (Fig. $3 A$ ) and $c$ RaclA (Fig. $3 D$ ) were similar (quantitation not shown); on the other hand, the changes during development of the two transcripts of 2.4 and $1.8 \mathrm{~kb}$ recognized by the $c R h o C$ probe (Fig. $3 C$ ) were different, showing highest levels of expression at E10 and E8, respectively (quantitation not shown).

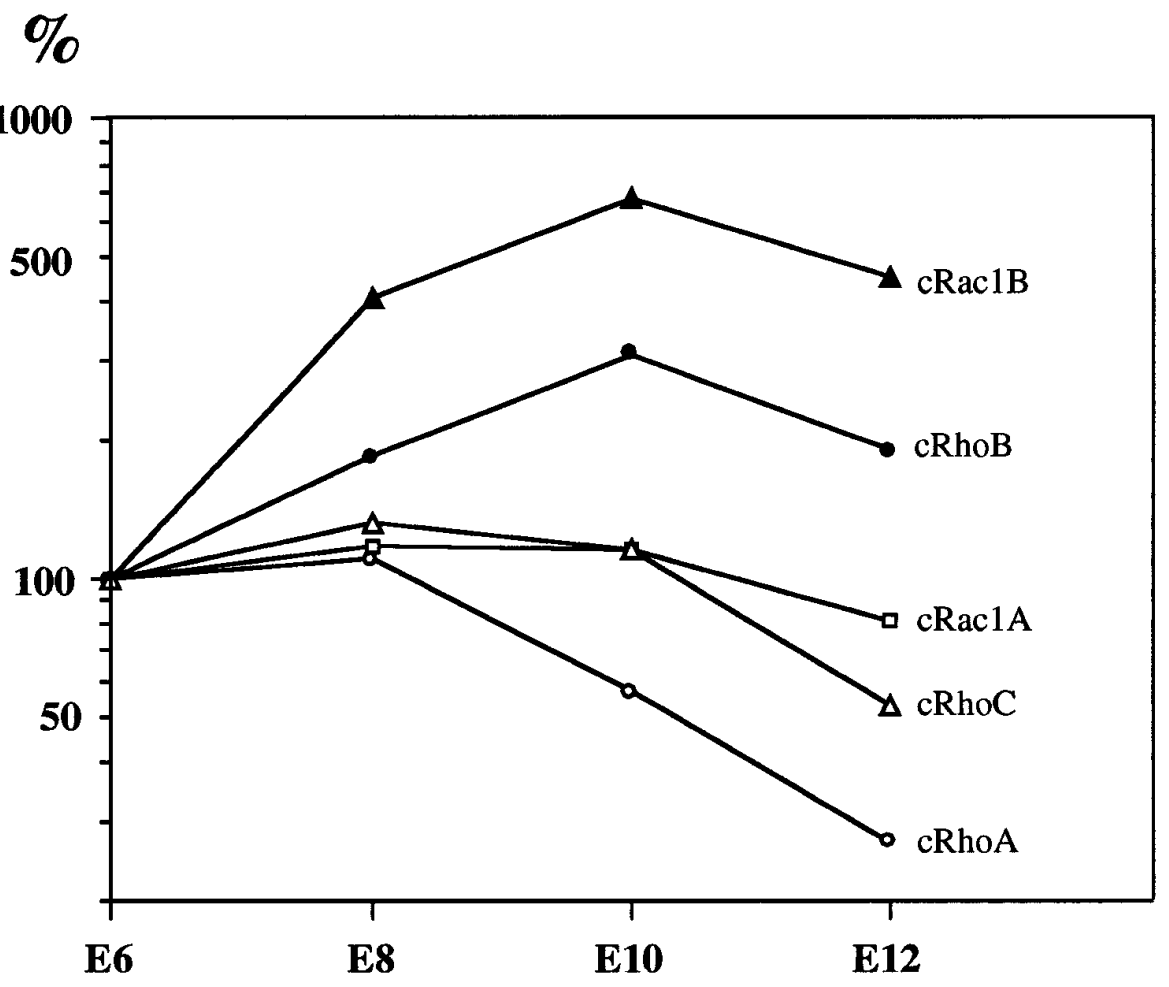




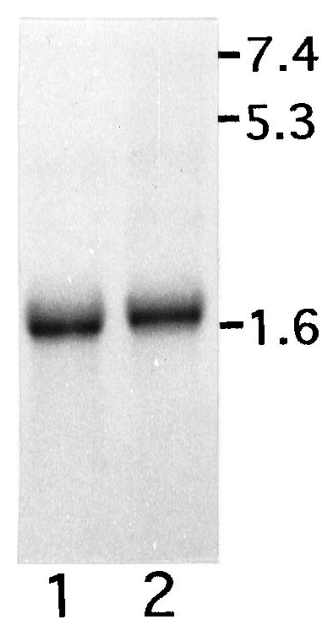

Figure 5. Expression of $c$ Rac1B mRNA in neurons and glia from developing neural retina. Fifteen micrograms of total RNA extracted from cultures enriched in retinal glial cells (lane 1) or in retinal neurons (lane 2) prepared from E7 retinas were electrophoresed on a 1\% agarose gel and transferred to filters, as described in Materials and Methods. Filters were incubated with a ${ }^{32} \mathrm{P}$-labeled probe specific for $c$ Rac1B. RNA markers (in kilobases) are indicated to the right.

into Kodak NTB-2 emulsion and exposed at $4^{\circ} \mathrm{C}$ for $15-21 \mathrm{~d}$. Sections hybridized to sense probes for the different genes were processed in parallel and used as controls for nonspecific hybridization. After development, the slides were counterstained with Hoechst 33258 and analyzed by dark-field illumination and by UV fluorescence.

Cell culture. Cultures enriched in retinal neurons and in retinal glia (Biscardi et al., 1993) were prepared from E7 chick retinas. Neural retinas were dissected and trypsinized, and cultures of retinal neurons were obtained under serum-free conditions as described (de Curtis et al., 1991). After $18 \mathrm{hr}$ in culture, neuronal cells were used to prepare total RNA as described above. For glial cells, cells from trypsinized retinas were cultured in DMEM with 5\% fetal calf serum. Confluent monolayers were transferred to new culture dishes to dilute neurons; remaining neurons were washed off the glial monolayers. Neuron-free monolayers were then used for total RNA preparation as described above.

Expression of cRac1B in retinal cells. The full-length cDNA for $c$ Rac1B was subcloned into pcDNA-I-Amp vector (Invitrogen, Carlsbad, CA) containing a sequence including the YDVPDYA amino acids of the influenza hemagglutinin (HA), and the pcDNA-I-HA-Rac1B plasmid obtained was used for transfections of primary retinal cells.

For transfections, we used a protocol modified from Boussif et al. (1995). Approximately 300,000 retinal cells obtained from E6 chick neural retinas were plated in each 1.5 -cm-diameter well containing a glass coverslip coated with $200 \mu \mathrm{g} / \mathrm{ml}$ poly-D-lysine and $40 \mu \mathrm{g} / \mathrm{ml}$ laminin. Cells were cultured overnight at $37^{\circ} \mathrm{C}, 5 \% \mathrm{CO}_{2}$ as described (de Curtis et al., 1991), to induce neurite extension. Cells were then incubated with $200 \mu \mathrm{l} /$ well of $150 \mathrm{~mm} \mathrm{NaCl}$ containing $150 \mathrm{nmol}$ of polyethylenimine (PEI $50 \mathrm{kDa}$; Sigma) and $5 \mu \mathrm{g}$ of pcDNA-I-HA-Rac1B plasmid in $0.5 \mathrm{ml}$ of transfection medium [50\% retinal growth medium (RGM), $50 \%$ DMEM, and 5\% fetal calf serum]. After $3 \mathrm{hr}$ of culture, the medium was replaced with serum-free RGM, and the cells were cultured for an additional $24 \mathrm{hr}$. Cells were then fixed with paraformaldehyde or with cold $\left(-20^{\circ} \mathrm{C}\right)$ methanol and processed for indirect immunofluorescence as described by Cattelino et al. (1995). Cells were incubated for $1 \mathrm{hr}$ at room temperature with the following primary antibodies: a monoclonal antibody against the HA-tag, a polyclonal antibody against the $200 \mathrm{kDa}$ neurofilament protein (Sigma), and a polyclonal antibody against the extracellular portion of the integrin $\alpha 6$ subunit (de Curtis and Reichardt, 1993). Cells were subsequently incubated for $30 \mathrm{~min}$ with TRITCconjugated sheep anti-mouse IgG together with FITC-conjugated sheep anti-rabbit IgG (Boehringer Mannheim) and observed using a ZeissAxiophot microscope.

\section{RESULTS \\ Cloning of five Rho family members expressed in chicken embryonic neural retina}

Our first aim has been the identification of members of the Rho family of GTPases expressed in developing neurons. For this purpose we have used RT-PCR using two sets of degenerate oligonucleotides to amplify fragments of transcripts of Rho family genes from RNA prepared from developing chick retinas, which have then been used to isolate cDNA clones from $\lambda \mathrm{gt} 10 \mathrm{cDNA}$ libraries.

Fragments of Rho family cDNAs were amplified by PCR from cDNAs prepared from E6 chick neural retina mRNAs. The PCR reactions were performed in the presence of either one of two sets of degenerated oligonucleotides: the oligonucleotides RhoA-1 and RhoA-2 corresponding to the $\mathrm{FSKD}(\mathrm{Q} / \mathrm{E}) \mathrm{FP}$ and $\operatorname{MKQEPV}(\mathrm{K} / \mathrm{R})$ peptides, specific for the human RhoA, B, and $\mathrm{C}$ proteins, and the oligonucleotides RhoF-1 and RhoF-2 corresponding to the KTCLLI and Y(L/M/V)ECSA peptides, specific for all known human Rho family members. Restriction analysis and sequencing of $\sim 100 \mathrm{cDNA}$ fragments obtained by PCR identified five different DNA sequences encoding proteins with a high degree of homology to known human Rho family members. The five different PCR fragments were used to screen two $\lambda \mathrm{gt} 10$ cDNA libraries, one from E10 chick embryo and one from E13 chick brain. In this way, several $\lambda$ phage clones were found that contain coding regions corresponding to the five identified chicken Rho family genes. Sequence analysis of the isolated clones (Fig. 1), and the comparison with the sequences of known human Rho proteins (Fig. $2 B, C$ ), allowed us to identify open reading frames coding for the predicted full-length polypeptides of four of the five genes. Several unsuccessful attempts were made to isolate from two available chick cDNA libraries a full-length clone for a fifth cDNA, for which no $5^{\prime}$ terminal sequence could be found (Fig. 2A, cRhoC).

Comparison at the nucleotide and polypeptide levels of the five chicken genes with the human Rho and Rac sequences (Fig. $2 B, C)$ revealed that three chicken Rho and two chicken Rac homologs had been isolated. We propose to name the five chicken genes $c R h o A, c R h o B, c R h o C, c R a c 1 A$, and $c R a c 1 B$. At the amino acid level, cRhoA is $100 \%$ identical to human RhoA, whereas cRhoB and cRhoC show $97.5 \%$ and $95.4 \%$ identity, respectively, to their human counterparts. For $c R h o C$, comparison with the respective human gene indicated that the sequence corresponding to the 19 amino terminal amino acid residues is missing. Interestingly, both $c R a c 1 A$ and $c R a c 1 B$ show the highest degree of identity with the human Rac1 sequence $88.5 \%$ and $80.7 \%$, respectively). Comparison of the polypeptide sequences derived from the chick clones with the human sequences (Fig. 2C) confirmed that the cRac1A polypeptide is $100 \%$ identical to the human Rac1 protein, whereas the cRac1B polypeptide is $93.7 \%$ identical to human Rac1, and only $89 \%$ identical to human Rac2. In particular, the $\mathrm{C}$-terminal portion of the cRac1B polypeptide sequence showed a much higher degree of identity for human Rac1 than for human Rac2 (not shown). We propose that $c$ Rac1B represents a new $R a c$ gene.

\section{Developmental regulation of expression of GTPases in the chicken retina}

To characterize in more detail the expression of the five identified Rho family transcripts during retinal development, we have analyzed their expression by Northern blot analysis (Fig. 3). Filters with total RNA prepared from neural retinas isolated from dif- 

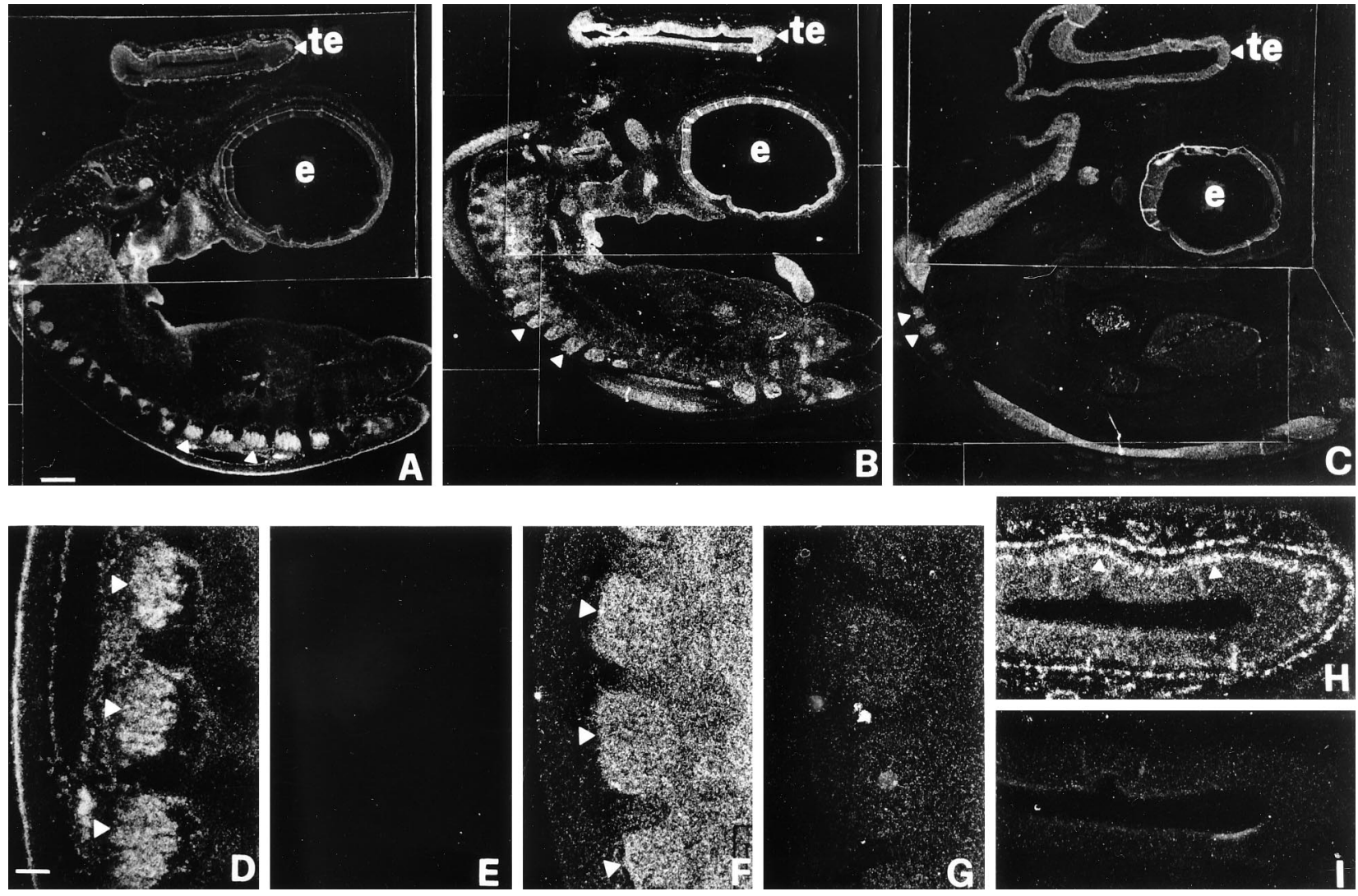

Figure 6. In situ hybridization for different GTP-binding proteins of the Rho family in E6.5 chick embryos. Parasagittal sections were incubated with antisense probes for $c R h o B(A), c R a c 1 A(B)$, and $c R a c 1 B(C)$. Differences can be detected in the overall distribution of the mRNA for these three proteins. At this stage, the three different mRNAs were strongly expressed in the developing nervous system. DRGs show high levels of expression of the three mRNAs (arrowheads). The expression of $c R h o B(D)$ and $c R a c 1 A(F)$ mRNAs in the DRGs is shown at higher magnification. $E$ and $G$ include similar fields from sections incubated with sense probes for $c R h o B$ and $c R a c 1 A$, respectively. In the tectum $(t e), c R a c 1 A(B)$ and $c R a c 1 B(C)$ mRNAs show a homogeneous distribution. In $H$, a higher magnification of the area of the tectum shown in $A$ reveals that $c R h o B$ mRNA is strongly expressed in an external layer (arrowheads) corresponding to presumptive postmitotic neuroepithelial cells. $I$ shows the area of the tectum from a control section incubated with a sense probe for $c R h o B$. $e$, Eye. Scale bars: $A-C, 100 \mu \mathrm{m} ; D-I, 25 \mu \mathrm{m}$.

ferent developmental stages (E6, E8, E10, and E12) were probed with random-primed ${ }^{32} \mathrm{P}$-labeled cDNAs. Distinct RNA hybridization patterns were obtained with each probe. A single band corresponding to 2.4 and $1.65 \mathrm{~kb}$ transcripts was detected for $c R h o B$ and $c R a c 1 B$, respectively (Fig. 3B,E), whereas two different bands were detected for $c R h o A, c R h o C$, and $c R a c 1 A$ (Fig. 3, $A, C$, and $D$, respectively). Two different RNA blots were probed for each transcript and quantitated by densitometric scanning (Fig. 4). The data presented in Figure 4 were obtained after normalizing the value for each transcript with the corresponding value obtained after hybridization for the $18 \mathrm{~S}$ RNA (not shown). For $c R h o A, c R h o C$, and $c R a c 1 A$, quantitations at each developmental stage represent the sum of the two transcripts (Fig. $3 A, C, D)$. The results show that the expression of the five transcripts is regulated differently during maturation of the retina. In particular, $c R h o B$ and $c R a c 1 B$ transcripts were upregulated during retinal development, whereas the other transcripts were downregulated (Fig. 4).

For the detection and quantitation of the $c R h o C$ transcripts, the blots had to be exposed for autoradiography 10 times longer compared with those for the other transcripts (Fig. 3C), suggesting that this gene is not as abundantly expressed as the other Rho family genes in the developing neural retina; on the other hand, we found that $c R h o C$ was highly expressed in non-neuronal chick cells (data not shown).

\section{Expression of $c$ Rac1B mRNA in neurons and glia from developing neural retina}

To check whether the newly identified, neural-specific cRac1B GTP-binding protein was present also in non-neuronal cells of the CNS, we prepared cultures enriched either in neurons or in glial cells from E7 neural retinas, as described in Materials and Methods. Northern blot analysis from gels loaded with the same amount of total RNA isolated from the two different cell preparations showed that similar amounts of the $1.65 \mathrm{~kb}$ cRaclB transcript were present in glial cells and neurons at this stage of development (Fig. 5, lanes 1 and 2, respectively).

\section{Differential distribution of Rho proteins in developing chicken embryos}

The differential expression of the identified Rho family transcripts during retinal development encouraged us to further characterize their expression in the developing chick nervous system by in situ hybridization. Because $c R h o C$ was poorly expressed in the neural retina compared with the other four genes, we limited the distribution studies to the four abundantly expressed $c R h o A$, $c R h o B, c R a c 1 A$, and $c R a c 1 B$ genes. Sections obtained from E6.5 and E8.5 chicken embryos were analyzed. The overall pattern of expression at E6.5 showed clear differences among the transcripts (Fig. 6). Those for $c$ RhoA (not shown) and $c$ RaclA (Fig. $6 B)$ were quite homogeneously distributed throughout the em- 

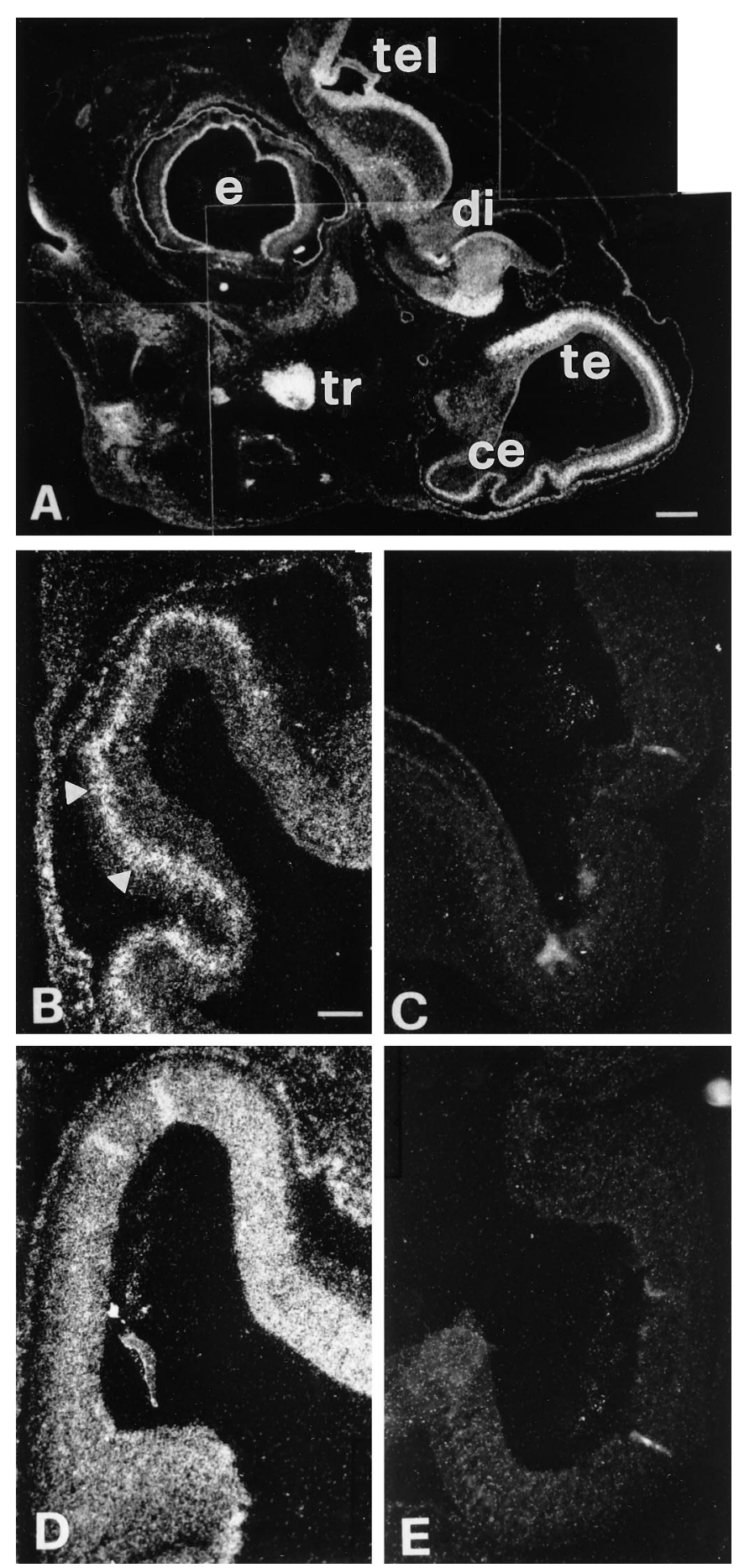

Figure 7. In situ hybridization for different GTP-binding proteins of the Rho family in E8.5 chick embryos. $A$, In situ hybridization of $c R h o B$ mRNA in parasagittal sections from E8.5 chick embryo head. Several structures of the developing nervous system show strong expression of $c R h o B$, including the retina in the eye $(e)$, the telencephalon $(t e l)$, the diencephalon ( $d i)$, the tectum (te), the cerebellum ( $c e$ ), and the trigeminal ganglion $(t r) . B$, Higher magnification of the developing cerebellum shows stronger expression of $c R h o B$ mRNA in the presumptive developing Purkinje cell layer (arrowheads). D, The developing cerebellum from a section similar to the one shown in $B$ shows a homogeneous expression of $c R h o A$ mRNA. In $C$ and $E$, sections incubated with sense probes for $c R h o B$ and $c R h o A$, respectively, are shown as controls. Scale bars: $A, 100$ $\mu \mathrm{m} ; B-E, 25 \mu \mathrm{m}$. bryo, whereas the distribution of $c R h o B$ (Fig. $6 A$ ) and $c$ Rac1B (Fig. $6 C$ ) transcripts was more restricted. In particular, $c R a c 1 B$ transcript seemed concentrated in the developing nervous system, including the retina, the tectum, the spinal cord, the dorsal root ganglia (DRGs), and the trigeminal ganglion (Fig. 6C). The same structures were labeled also by $c R h o B, c R a c 1 A$ (Fig. 6, $A$ and $B$, respectively), and $c R h o A$ (not shown) antisense probes. At higher magnification, DRGs labeling for $c R h o B$ (Fig. 6D) appeared concentrated on the more dorsal half of the structures, quite different from the distributions of $c R a c 1 A$ (Fig. $6 F$ ), $c$ Rac1B, and $c R h o A$ (not shown), which were homogeneous throughout the ganglia. Differences were also observed in the labeling of the developing tectum. In fact, although the overall distribution of the $c R a c 1 A$ and $c R a c 1 B$ transcripts in this structure appeared homogeneous (Fig. 6, $B$ and $C$, respectively), at higher magnification $c R h o B$ staining was stronger in the external layer, presumably corresponding to postmitotic neurons derived from the neuroepithelium (Fig. 6H).

Similar to what we observed at E6.5, in E8.5 embryos the patterns of distribution of the transcripts for $c R h o A$ and $c R a c 1 A$ were more homogeneous than those for $c R h o B$ and $c R a c 1 B$ (not shown). In contrast, the $c R a c 1 B$ transcript was highly concentrated in the developing nervous system (not shown), whereas the distribution of $c R h o B$, although somewhat more widespread in comparison with $c R a c 1 B$, showed several interesting features within different structures of the developing nervous system. Figure $7 A$ shows a low-power magnification of a parasagittal section of an E8.5 chicken head, incubated with an antisense probe for $c R h o B$. Several structures of the developing nervous system, including a very bright area below the eye corresponding to the trigeminal ganglion, express high levels of the transcript. Higher magnification of the developing cerebellum at E8.5 showed that $c R h o B$ was highly concentrated in the presumptive Purkinje cell layer (arrowheads, Fig. $7 B$ ), whereas $c R h o A$ was distributed homogeneously throughout the entire region (Fig. 7D). The distribution of both $c R a c 1 A$ and $c R a c 1 B$ transcripts was similar to that of $c R h o A$, although the signal was not as strong (not shown). Higher magnification of the eye region showed a clear concentration of the $c R h o B$ transcript in the retinal ganglion cell (RGC) layer of E8.5 retinas (arrows, Fig. $8 C$ ). In contrast, $c R h o A$ was distributed homogeneously within the neural retina (Fig. $8 A$ ). The distribution of $c R a c 1 B$ was similar to that of $c R h o B$, although weaker (not shown), whereas the expression pattern of $c$ RaclA was similar to that of $c R h o A$ (not shown). At E6.5, the distribution of the different transcripts in the neural retina was similar to that observed in E8.5 embryos, although the concentration of the $c R h o B$ transcript in the RGC layer was not as distinct, probably because of the presence of a less defined ganglion cell layer at this stage (not shown).

The distribution of the transcripts in the spinal cord was analyzed in transversal/oblique sections from E6.5 and E8.5 embryos. Interestingly, three different patterns were revealed by in situ analysis. At E6.5, the expression of $c R a c 1 B$ was quite homogeneous throughout the section of the spinal chord (Fig. 9D). In contrast, $c$ Rho $A$ and $c$ Rac $1 A$ (Fig. 9, $A$ and $C$, respectively) were concentrated around the ventricular zone, where proliferation is occurring, and in the ventral area of the spinal chord, where motor neurons are located. Finally, a third pattern was observed for $c R h o B$ (Fig. 9B), which was highly expressed in the ventral portion of the spinal cord, including the floor plate and the area with motor neurons. At this stage, DRGs visible on the side of the spinal cord were positive for all four tested GTP-binding protein 

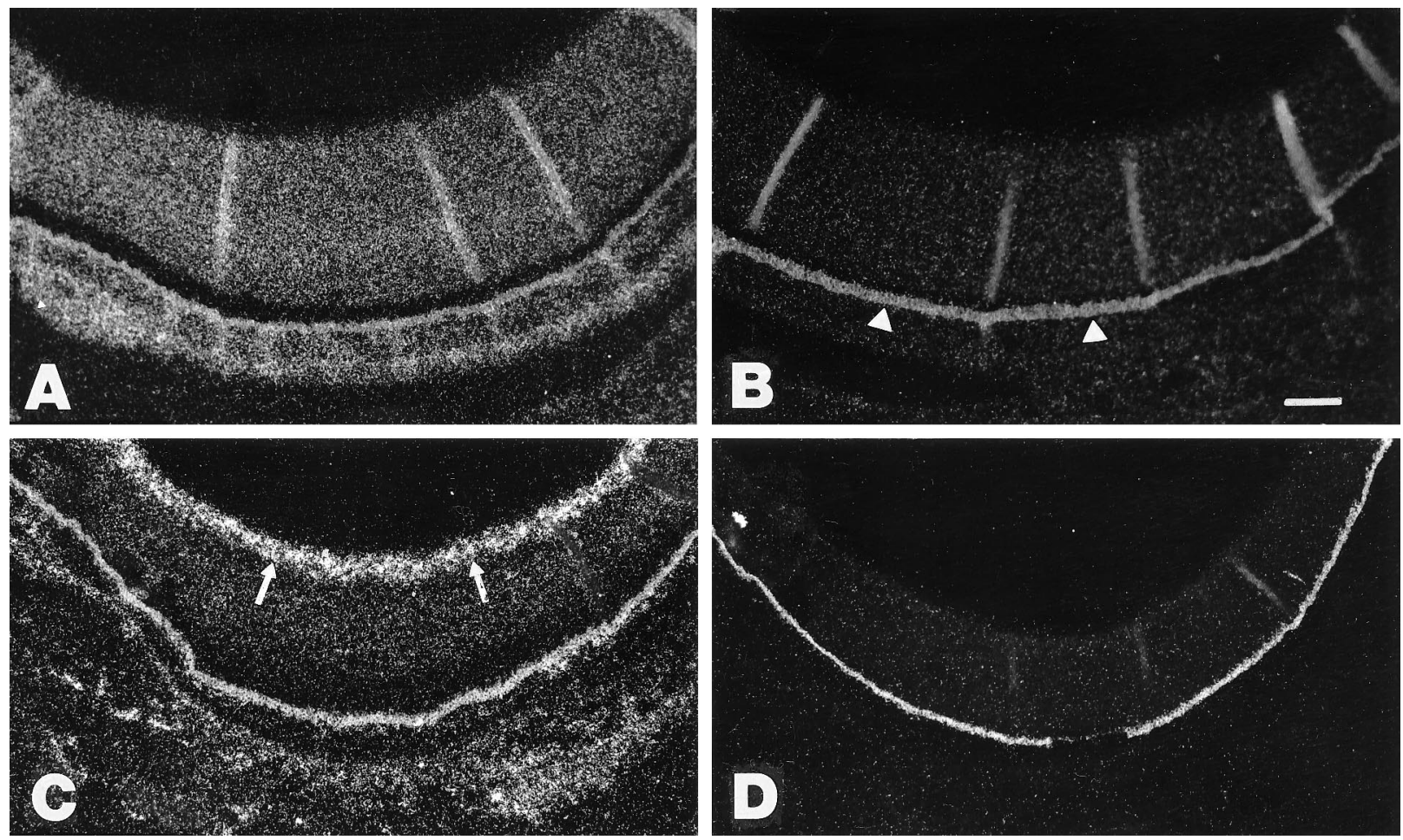

Figure 8. Expression of Rho GTPases in the developing chick retina. Expression of $c R h o A(A, B)$ and $c R h o B(C, D)$ mRNAs in the developing chick retina. Antisense $(A, C)$ and sense $(B, D)$ probes obtained from the respective cDNAs were incubated with sections from E8.5 chick embryos. Diffuse staining of the neural retina is observed for $c R h o A(A)$, whereas stronger labeling is observed in the RGC layer (arrows) for $c R h o B(C)$. The nonspecific signal given by the retinal pigmented epithelium is indicated by arrowheads in $B$. Scale bar, $25 \mu \mathrm{m}$.

mRNAs. At E8.5 the pattern of distribution of $c R h o A$ and $c R a c 1 A$ was similar to that observed at E6.5, although the differences in the intensity of the signal among distinct areas were not as clear (not shown); a stronger, still homogeneous signal was found for $c R a c 1 B$ (Fig. $9 F$ ), whereas the distribution of the $c R h o B$ transcript seemed more restricted than in E6.5 spinal cord and was localized to the motor neuron region and the floor plate (Fig. 9E).

\section{Distribution of the cRac1B polypeptide in retinal neurons}

The distribution of the $\mathrm{cRac} 1 \mathrm{~B}$ protein in retinal neurons was studied by expressing an epitope-tagged form of the protein. Cultured primary retinal neurons were transiently transfected with the pcDNA-I-HA-Rac1B vector containing the sequence encoding for an HA-tagged cRac1B protein. We obtained the best transfection efficiencies by using PEI $50 \mathrm{kDa}$ on E6 retinal cells that had been cultured for $\sim 12 \mathrm{hr}$ before treatment. Immunofluorescence with an anti-HA antibody showed that cRac1B was homogeneously distributed in retinal cells (Fig. 10). In particular, cRac1B was also visible along neurites and in all their protrusions. Double immunofluorescence staining was used to identify transfected neurons expressing a $200 \mathrm{kDa}$ neurofilament polypeptide (Fig. 10A,B). Neurofilament-negative cells expressing the HA-Rac1B construct were also present in culture (not shown). The distribution of the epitope-tagged cRac1B in neurons showed a pattern similar to that of the integrin $\alpha 6$ subunit, which is expressed on the surface of these cells (Fig. 10C,D), suggesting a possible association of the Rac1B polypeptide with the plasma membrane.

\section{DISCUSSION}

Five major conclusions can be drawn from the data presented in this paper. First, developing neural retinal cells express mRNAs coding for at least five components of the Rho family of GTPases: three coding for Rho proteins and two coding for Rac proteins. Second, the comparison of the cDNAs with the human homologs indicates that one of the Rac proteins represents a novel Rac gene. Third, the levels of expression of the five transcripts are differentially regulated during the development of the retina. Fourth, four of the identified transcripts show distinct patterns of distribution in developing chick embryos, with particularly high levels of expression of all the transcripts, and prominent localization of the newly identified $c R a c 1 B$ gene in the developing nervous system. Finally, the expression of an epitope-tagged form of cRac1B in primary retinal neurons reveals a homogeneous distribution of the polypeptide in the cell body and along neurites. These results demonstrate for the first time that Rho family GTPases are highly expressed in the developing CNS and peripheral nervous system, suggesting that these GTPases play an important role during the development of the vertebrate nervous system.

Several extracellular cues, including extracellular matrix glycoproteins, can induce dramatic morphological changes in the developing neurons, which result in the formation of neurites (Sanes, 1989; de Curtis, 1991; Reichardt and Tomaselli, 1991). We have shown previously that the dramatic effects of laminin on neurite extension from retinal neurons in culture are mediated by the $\alpha 6 \beta 1$ integrin laminin receptor (de Curtis and Reichardt, 1993). The molecular mechanisms underlying these processes remain poorly understood. Recent studies in non-neuronal cells 

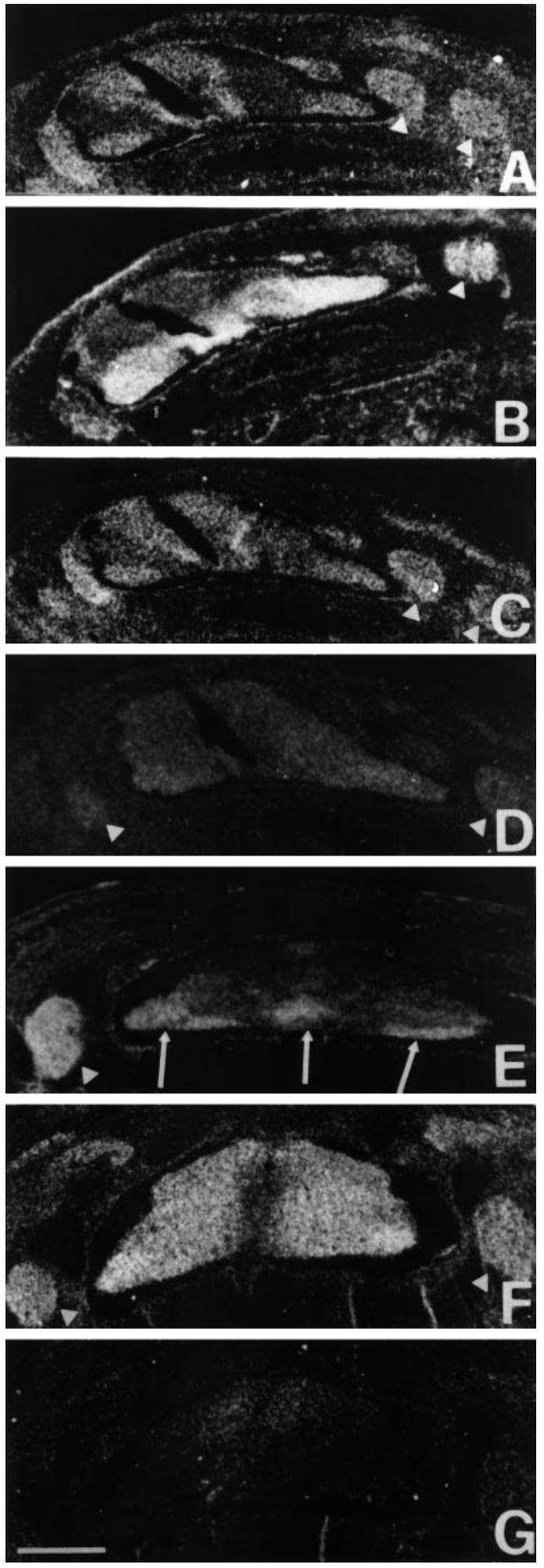

Figure 9. Expression of Rho GTPases in the developing spinal cord Sections including the spinal cord of E6.5 $(A-D)$ and E8.5 $(E-G)$ chick embryos were incubated with antisense probes for $c R h o A(A), c R h o B(B$, $E), c R a c 1 A(C)$, and $c \operatorname{Rac1B}(D, F)$, and with a sense probe for $c R a c 1 B$ $(G)$ as a control. Different patterns of expression can be observed for the different mRNAs. DRGs (arrowheads) can be observed on the sides of the spinal cord. In $A-D$ the more oblique sections included two DRGs on one side of the spinal cord. In $E$, arrows indicate the localization of $c R h o B$ transcript in E8.5 spinal cord, mainly restricted to the motor neuron regions and to the floor plate (central arrow). Scale bar, $100 \mu \mathrm{m}$. have shown that Rho family GTPases regulate the formation of actin-based structures such as filopodia, lamellipodia, and stress fibers (Nobes and Hall, 1995). Although stress fibers are not found in growth cones, filopodia and lamellipodia are actindependent processes also involved in growth cone navigation. Moreover, recent data postulate the involvement of Rho family GTPases in the regulation of actin-mediated growth cone migration (Jalink et al., 1994; Postma et al., 1996). In addition to their role in cytoskeletal reorganization, Rho family GTPases have been involved in the regulation of the activity of transcription factors and in membrane traffic (Ridley, 1996). Furthermore, a number of possible effectors for these GTPases have been identified recently (for review, see Ridley, 1996).

With the aim of studying the role of these GTPases during the development of the neuronal phenotype, we have looked for cDNA clones of Rho family GTPases expressed in primary neurons. We have used E6 retinas as the source of mRNA for this study, because this is the stage at which cultured retinal neurons respond to laminin by extending neurites. Three of the identified small GTP-binding proteins expressed by neural retinal cells correspond to the chick homologs of the already known human $R h o A, R h o B$, and $R h o C$ genes (Madaule and Axel, 1985). Two other cDNAs were related to Rac genes and predicted two different Rac proteins, one showing complete identity (cRac1A) and the other showing a high degree of identity (cRac1B) to human Rac1. We think that the cRac1B protein does not correspond to the chick homolog of human Rac2, because cRac1B shows a higher degree of identity to the human Rac1 than to human Rac2 at both the nucleotide and protein level. Furthermore, although the Racl gene is known to be expressed in various tissues and cell lines, the expression of Rac2 is restricted to cells of the hemopoietic lineage (Didsbury et al., 1989; Shirsat et al., 1990; Moll et al., 1991).

The temporal expression of the transcripts coding for the different identified chicken GTPases during the development of the neural retina has been investigated. Our data show that the five transcripts are differentially regulated between E6 and E12; in fact, although the expression of $c R h o A$ decreased after E8 and that of $c R a c 1 A$ and $c R h o C$ decreased after E10, the expression of $c R a c 1 B$ and $c R h o B$ showed an increase between E6 and E10 and a decrease afterward. Between E6 and E12, neural retinal cells migrate and organize into the different layers that are recognizable in the mature retina. Furthermore, the RGCs, which form at E6 the only clearly identifiable neuronal layer of the retina, do actively extend their axons toward their target, the optic tectum. The first axons of the RGC layer reach the optic tectum at E6, and by E12 all of them have reached the target. Extracellular matrix components are expressed along virtually the entire embryonic retinotectal pathway (McLoon, 1984; Adler et al., 1985; Cohen et al., 1987; Halfter and Fua, 1987; McLoon et al., 1988; Bartsch et al., 1995). In the optic stalk, laminin expression is transient and correlates with the ability of RGCs to use laminin as a substrate (Cohen et al., 1987, 1989). Similarly, expression of tenascin in the tectum at the time of innervation by RGC axons has been correlated with the capacity of these neurons to extend neurites on tenascin in culture (Bartsch et al., 1995). Interestingly, in situ hybridization revealed accumulation of $c R h o B$ transcript in the RGC layer that was particularly evident at E8.5, and also of $c R a c 1 B$, although the accumulation was less dramatic, whereas $c R h o A$ and $c R a c 1 A$ were homogeneously distributed in the whole neural retina. Moreover, the 

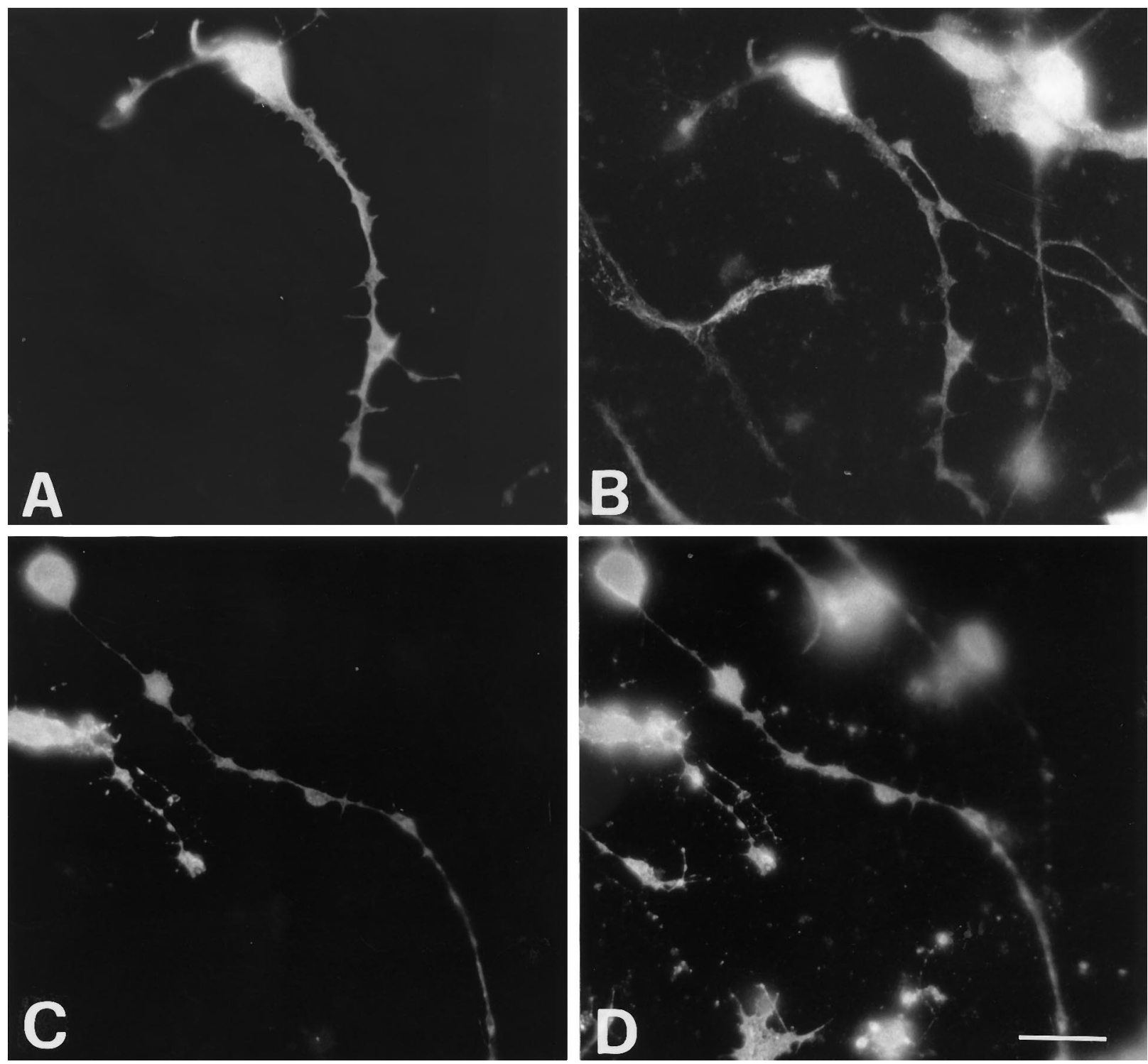

Figure 10. Distribution of cRac1B in cultured retinal neurons. Retinal neurons grown on laminin were transfected with the pcDNA-I-HA-Rac1B plasmid as described in Materials and Methods, and the cells were analyzed by immunofluorescence $24 \mathrm{hr}$ after transfection. In $A$ and $B$, cells were fixed with paraformaldehyde and permeabilized with $0.1 \%$ Triton X-100. In $C$ and $D$, cells were fixed and permeabilized with cold $\left(-20^{\circ} \mathrm{C}\right)$ methanol. Primary antibodies were monoclonal antibody against $\mathrm{HA}(A, C)$, polyclonal antibody against $200 \mathrm{kDa}$ neurofilament protein $(B)$, and polyclonal antibody against the integrin $\alpha 6$ subunit $(D)$. Same fields are represented in $A$ and $B$ and in $C$ and $D$ ). Scale bar, $10 \mu \mathrm{m}$.

expression of all studied Rho family GTPases was decreased by E12, when retinal layers have formed and all RGC axons have reached the optic tectum. Because Rho and Rac proteins have been implicated in the organization of the actin cytoskeleton, one hypothesis is that the observed expression of these proteins in RGCs may be required for the process of neuritogenesis, which occurs at this time of development.

Another aim of this study was the analysis of the distribution of the identified GTPases in the developing chick embryo. A striking result from this study is the observation that $c R h o A$, $c R h o B, c R a c 1 A$, and $c R a c 1 B$ are strongly expressed in the developing nervous system. In fact, in situ hybridization on sections from E6.5 and E8.5 embryos showed strong labeling of both CNS and peripheral nervous system. At both stages, DRGs showed high levels of expression of the transcripts, and a more detailed analysis showed differences in the pattern of expression that were particularly evident for $c R h o B$ and $c R a c 1 A$. The observed strong $c R h o B$ expression in trigeminal ganglia may be correlated with the innervation of the target by the axons of the trigeminal sensory neurons that is actively occurring at this stage (Windle and Austin, 1936; Moody et al., 1989). Clear differences were detected in the localization of the different GTPase transcripts within the spinal cord. The specific localization of $c R h o B$ transcripts in layers of the developing $\mathrm{CNS}$, in contrast to the homogeneous distribution of the transcripts of other GTPases within the same structures, also suggests specific and different functions of distinct members of the Rho family during neuronal development. Such a conclusion is corroborated by recent studies in invertebrates that have shown Caenorhabditis elegans RhoA to be expressed at highest levels during embryogenesis and particularly enriched in the pharyngeal nerve ring and at the tip of the head 
containing chemosensory and mechanosensory neurons (Chen and Lim, 1994). Furthermore, the Drosophila DRac1 and $D C d c 42$, are also highly expressed in the nervous system, where they are involved in axonal outgrowth (Luo et al., 1994). Interestingly, we found that all four genes analyzed in this paper are expressed in the chicken developing cerebellum and that $c R h o B$ is concentrated in the presumptive Purkinje cell layer. This might correlate with the recent observation that perturbation of Rac1 activity in mice Purkinje cells leads to modifications of the axonal and dendritic structures of these cells (Luo et al., 1996).

Expression of an epitope-tagged cRac1B has allowed the analysis of the distribution of this new neural-specific Rac in primary neurons. The cellular localization of $\mathrm{cRac} 1 \mathrm{~B}$ is similar to that of the integrin $\alpha 6$ subunit, a known plasma membrane component, suggesting a possible association of cRac1B with the plasma membrane of neurons, although further work is required to prove association of this protein with the plasma membrane. Like the other members of the family, cRac1B has a C-terminal motif that can be isoprenylated and could account for its possible association to the plasma membrane. In particular, cRac1B is uniformly expressed along actin-rich neurites and their protrusions. This localization could correspond to a prerequisite for the rapid reorganization of the actin cytoskeleton during filopodia extension, a process required for neurite extension or neurite branching, and future work will be aimed at exploring this issue.

In conclusion, the results presented in this paper have shown for the first time that various members of the Rho family of small GTP-binding proteins are differentially and specifically expressed in the CNS and peripheral nervous system of chicken embryos in concomitance with complex events of neuronal differentiation. In view of the widely accepted role of these proteins in multiple aspects of cell physiology, these observations strongly support an important role for Rho family GTPases in the acquisition of the mature neuronal phenotype.

\section{REFERENCES}

Adler R, Jerdan J, Hewitt AT (1985) Responses of cultured neural retinal cells to substratum-bound laminin and other extracellular matrix molecules. Dev Biol 112:100-114.

Bartsch S, Husmann K, Schachner M, Bartsch U (1995) The extracellular matrix molecule tenascin: expression in the developing retinotectal system and substrate properties for retinal ganglion cell neurites in vitro. Eur J Neurosci 7:907-916.

Biscardi JS, Cooper NGF, Maness PF (1993) Phosphotyrosine-modified proteins are localized in Müller cells of the chick neural retina. Exp Eye Res 56:281-289.

Boussif O, Lezoualc'h F, Zanta MA, Mergny MD, Scherman D, Demeneix B, Behr JP (1995) A versatile vector for gene and oligonucleotide transfer into cells in culture and in vivo: polyethylenimine. Proc Natl Acad Sci USA 92:7297-7301.

Cattelino A, Longhi R, de Curtis I (1995) Differential distribution of two cytoplasmic variants of the $\alpha 6 \beta 1$ integrin laminin receptor in the ventral plasma membrane of embryonic fibroblasts. J Cell Sci 108:3067-3078.

Chen W, Lim L (1994) The Caenorhabditis elegans small GTP-binding protein RhoA is enriched in the nerve ring and sensory neurons during larval development. J Biol Chem 269:32394-32404.

Chomczynski P, Sacchi N (1987) Single-step method of RNA isolation by acid guanidinium thiocyanate-phenol-chloroform extraction. Anal Biochem 162:156-159.

Church GM, Gilbert W (1984) Genomic sequencing. Proc Natl Acad Sci USA 81:1991-1995.

Cohen J, Burne JF, McKinlay C, Winter J (1987) The role of laminin and the laminin/fibronectin receptor complex in the outgrowth of retinal ganglion cell axons. Dev Biol 122:407-418.

Cohen J, Nurcombe V, Jeffrey P, Edgar D (1989) Developmental loss of functional laminin receptors on retinal ganglion cells is regulated by their target tissue, the optic tectum. Development 107:381-387.

de Curtis I (1991) Neuronal interactions with extracellular matrix. Curr Opin Cell Biol 3:824-831.

de Curtis I, Reichardt LF (1993) Function and spatial distribution in developing chick retina of the laminin receptor $\alpha 6 \beta 1$ and its isoforms. Development 118:377-388.

de Curtis I, Quaranta V, Tamura RN, Reichardt LF (1991) Laminin receptors in the retina: sequence analysis of the chick integrin $\alpha 6$ subunit. J Cell Biol 113:405-416.

Didsbury J, Weber RF, Bokoch GM, Evans T, Snyderman R (1989) Rac, a novel ras-related family of proteins that are botulinum toxin substrates. J Biol Chem 264:16378-16382.

Don RH, Cox PT, Wainwright BJ, Baker K, Mattick JS (1991) “Touchdown" PCR to circumvent spurious priming during gene amplification. Nucleic Acids Res 19:4008.

Feinberg AP, Vogelstein B (1983) A technique for radiolabeling DNA restriction endonuclease fragments to high specificity activity. Anal Biochem 132:6-13.

Halfter W, Fua CS (1987) Immunohistochemical localization of laminin, neural cell adhesion molecule, collagen type IV and T-61 antigen in the embryonic retina of the japanese quail by in vivo injection of antibodies. Cell Tissue Res 249:487-496.

Hall A (1994) Small GTP-binding proteins and the regulation of the actin cytoskeleton. Annu Rev Cell Biol 10:31-54.

Jalink K, van Corven EJ, Hengeveld T, Morii N, Narumiya S, Moolenar WH (1994) Inhibition of lysophosphatidate- and trombin-induced neurite retraction and neuronal cell rounding by ADP ribosylation of the small GTP-binding protein Rho. J Cell Biol 126:801-810.

Lehrach H, Diamond D, Wozney JM, Boedtker H (1977) RNA molecular weight determinations by gel electrophoresis under denaturing conditions: a critical reexamination. Biochemistry 16:4743-4751.

Luo L, Liao YJ, Jan LY, Jan YN (1994) Distinct morphogenetic functions of similar small GTPases: Drosophila Drac1 is involved in axonal outgrowth and myoblast fusion. Genes Dev 8:1787-1802.

Luo L, Hensch TK, Ackerman L, Barbel S, Jan LY, Jan YN (1996) Differential effects of Rac GTPase on Purkinje cell axons and dendritic trunks and spines. Nature 379:837-840.

Mackay FJG, Nobes CD, Hall A (1995) The Rho's progress: a potential role during neuritogenesis for the Rho family of GTPases. Trends Neurosci 18:496-501.

Madaule P, Axel R (1985) A novel ras-related gene family. Cell 41:31-40.

Malosio ML, Grenningloh G, Kuhse J, Schmieden V, Schmitt B, Prior P, Betz H (1991) Alternative splicing generates two variants of the $\alpha 1$ subunit of the inhibitory glycine receptor. J Biol Chem 266:2048-2053.

Marchuk D, Drumm M, Saulino A, Collins FS (1991) Construction of T-vectors, a rapid and general system for direct cloning of unmodified PCR products. Nucleic Acids Res 19:1154.

McLoon SC (1984) Development of the retinotectal projection in chicks. In: Organizing principles of neural development (Sharma SC, ed), pp 325-342. New York: Plenum.

McLoon SC, McLoon LK, Palm SL, Furcht LT (1988) Transient expression of laminin in the optic nerve of the developing rat. J Neurosci 8:1981-1990.

Moll J, Sansig G, Fattori E, van der Putten H (1991) The murine rac1 gene: cDNA cloning, tissue distribution and regulated expression of rac1 mRNA by disassembly of actin microfilaments. Oncogene 6:863-866.

Moody SA, Quigg MS, Frankfurter A (1989) Development of the peripheral trigeminal system in the chick revealed by an isotypespecific anti-beta-tubulin monoclonal antibody. J Comp Neurol 279:567-580.

Nobes CD, Hall A (1995) Rho, Rac, and Cdc42 GTPases regulate the assembly of multimolecular focal complexes associated with actin stress fibers, lamellipodia, and filopodia. Cell 81:53-62.

Postma FR, Jalink K, Hengeveld T, Moolenar WH (1996) Sphingosine-1-phosphate rapidly induces Rho-dependent neurite retraction: action through a specific cell surface receptor. EMBO J 15:2388-2395.

Reichardt LF, Tomaselli KJ (1991) Extracellular matrix molecules and their receptors: functions in neural development. Annu Rev Neurosci 14:531-570. 
Ridley AJ (1996) Rho: theme and variations. Curr Biol 6:1256-1264.

Ridley AJ, Hall A (1992) The small GTP-binding protein Rho regulates the assembly of focal adhesion and actin stress fibers in response to growth factors. Cell 70:389-399.

Ridley AJ, Paterson HF, Johnston CL, Diekmann D, Hall A (1992) The small GTP-binding protein rac regulates growth factor-induced membrane ruffling. Cell 70:401-410.

Rugarli EI, Lutz B, Kuratani SC, Wawersik S, Borsani G, Ballabio A, Eichele G (1993) Expression pattern of the Kallmann syndrome gene in the olfactory system suggests a role in neuronal targeting. Nat Genet $4: 19-26$.

Sanes JR (1989) Extracellular matrix molecules that influence neural development. Annu Rev Neurosci 12:491-516.
Sanger F, Nicklen S, Coulson AR (1977) DNA sequencing with chainterminating inhibitors. Proc Natl Acad Sci USA 74:5463-5467.

Shirsat NV, Pignolo RJ, Kreider BL, Rovera G (1990) A member of the ras gene superfamily is specifically expressed in $\mathrm{T}, \mathrm{B}$ and myeloid hemopoietic cells. Oncogene 5:769-772.

Tanaka E, Sabry J (1995) Making the connection: cytoskeletal rearrangements during growth cone guidance. Cell 83:171-176.

Timpl R, Rhode H, Gehron-Robey P, Rennard S, Foidart J-M, Martin G (1979) Laminin, a glycoprotein from basement membrane. J Biol Chem 254:9933-9937.

Windle WF, Austin AM (1936) Neurofibrillar development in the central nervous system of chick embryos up to 5 days' incubation. J Comp Neurol 63:431-463. 